$$
\text { Artigos Originais }
$$




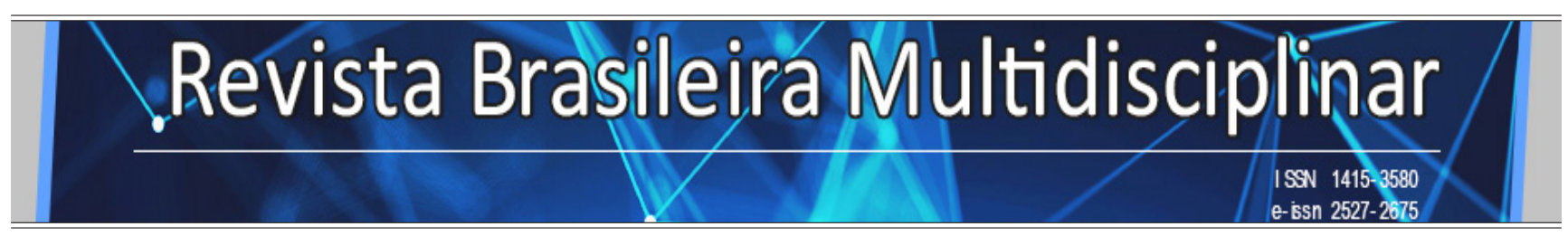

http://revistarebram.com/index.php/revistauniara

\section{CONHECIMENTO dos GRAdUANDos DE ENFERMAGEM SOBRE A PASSAGEM DE PLANTÃo}

Letícia Aparecida Sotrati ${ }^{\star}$; Luana Cristina Carrino*; Adriana Aparecida Mendes ${ }^{\star * *}$; Aline Helena Appoloni ${ }^{\star * * *}$; Silvia Helena Tognoli*****; Cibele Correia Semeão Binotto ${ }^{* * * * *}$.

${ }^{*}$ Graduandas do curso de enfermagem pela Universidade de Araraquara- UNIARA.

${ }^{*}$ Doutora em Ciências pelo Programa de Pós-Graduação em Enfermagem em Saúde Pública pela Escola de Enfermagem de Ribeirão Preto da Universidade de São Paulo.

${ }^{* * *}$ Enfermeira doutora em Ciencias pela Universidade de São Paulo e docente da Universidade Federal de São Carlos- UFSCar.

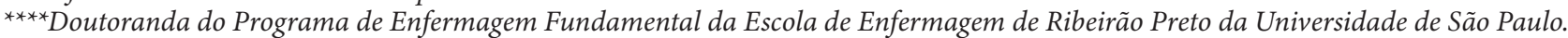

*****Doutoranda do Programa de Pós Graduação da Universidade Federal de São Carlos.

*Autor para correspondência e-mail: lets96@hotmail.com

\section{Palavras-chave}

Passagem de Plantão

Comunicação

Segurança do Paciente

Pnfermagem

\section{KEYWORDS}

Change-of-Shift Report

Communication

Patient Safety

Nursing

\section{RESUMO}

Objetivo: Identificar o conhecimento dos graduandos de enfermagem sobre a importância da passagem de plantão. Método: pesquisa de campo, de natureza exploratória com abordagem qualitativa. A amostra foi composta por 69 graduandos de enfermagem em uma instituição de ensino superior no interior no estado de São Paulo. A coleta de dados ocorreu em junho de 2016, os dados foram analisados por meio da análise temática. Resultados: Segundo a percepção dos graduandos os fatores que interferem nesse processo são a falta de comprometimento, comunicação prejudicada, ruídos e pressa em finalizar o plantão. Os facilitadores são a boa comunicação, ambiente adequado, bom relacionamento em equipe, uso de um instrumento. Conclusão: os graduandos reconhecem a passagem de plantão como uma ferramenta importante para garantir a continuidade do cuidado seguro. Melhorias como uma boa comunicação, ambiente adequado e o uso de instrumentos são apontados como facilitadores dessa etapa do cuidado.

\section{KNOWLEDGE OF NURSING UNDERGRADUATES ABOUT CHANGE-OF-SHIFT REPORT}

Objective: To identify the knowledge of nursing undergraduates about the importance of change-ofshift report. Method: Field research, based on exploratory and qualitative approach. The sample was consisted of 69 undergraduate nursing students at a higher education institution in the countryside of the state of São Paulo. The collection date took place in June 2016, and it was analyzed through the thematic analysis. Result: According to the perceptionof the undergraduates are interfere in this process the lack of commitment, impaired communication, noise, and haste in the ending of the shift. Some aspects that facilitate this process are good communication, proper environment, good team relationship, the use of the a checklist. Conclusion: Undergraduates recognize the shift as an important tool to ensure continuity of safe care. Improvements such as good communication, adequate environment and the use of checklist are pointed out as facilitators of this stage of care. 


\section{INTRODUÇÃo}

A comunicação é um elemento essencial do cuidado em enfermagem e também a base para o desenvolvimento das boas relações interpessoais, e quando bem executada pode garantir uma relação humanizada e efetiva mediante o cuidado em saúde. Para desenvolver uma assistência de qualidade é essencial que o enfermeiro seja capaz de compreender sobre o estado clínico do paciente, identificar quais foram as condutas tomadas e as mudanças no seu estado de saúde. Assim para ajudar nessa compreensão o processo comunicativo é a base das relações interpessoais que pode ou não refletir em um cuidado qualificado e humanizado (BROCA; FERREIRA, 2012).

No contexto hospitalar a troca de informações a respeito dos pacientes internados, entre os profissionais da saúde e principalmente entre a equipe de enfermagem, é um componente fundamental do processo de trabalho. Para garantir a assistência necessária aos pacientes, nas 24 horas de trabalho, as informações devem ser trocadas entre os diferentes turnos de trabalho, deste modo é fundamental que a comunicação ocorra de forma efetiva.

A passagem de plantão é o momento em que ocorre a troca de informações entre profissionais de saúde, assim é um instrumento de trabalho para a organização e planejamento dos cuidados de enfermagem, esse instrumento tem como finalidade transmitir informação clara e concisa sobre os acontecimentos que envolvem a assistência direta ao paciente, durante um período de trabalho e nesse contexto a habilidade de comunicação precisa estar desenvolvida para facilitar esse processo (SOUSA; BERNARDINO, 2015).

Dessa forma a passagem de plantão faz parte do processo de comunicação da equipe de enfermagem e está intrinsecamente relacionada a realização dos cuidados desses trabalhadores para com o paciente. Ressaltando que o não desenvolvimento de forma adequada pode acarretar em eventos adversos gerando consequências diretas e indiretas ao paciente e seus familiares, à instituição e à equipe (GONÇALVES et al., 2016). Esse processo comunicativo auxilia na organização do cuidado de enfermagem, e busca resultados para o cuidado seguro e de qualidade. A falta da passagem de plantão configura em infração ética disciplinar, inclusive com punição e penas descritas no código de ética dos profissionais de enfermagem (COREN, 2015).

Uma instituição bem organizada, com clareza no seu processo comunicativo entre os profissionais favorece um cuidado seguro. O cuidado seguro é uma característica da boa qualidade da assistência e a segurança do paciente tem ganhado destaque na agenda política de diversos países, inclusive do Brasil (BRASIL, 2016). Atualmente, a formação em enfermagem tem buscado responder os diferentes desafios em formar profissionais qualificados para atuar na prática assistencial e que contemplem as diferentes competências exigidas para a categoria. Partindo do princípio que a comunicação forma uma base para o relacionamento entre profissional paciente e posteriormente entre a equipe de saúde, essa deve ser trabalhada com os futuros enfermeiros desde o seu processo formativo. Dessa forma, se faz necessário estudar o processo de comunicação desde a graduação para a correta execução desta ferramenta que é passagem de plantão, isso implicará na continuidade da assistência com qualidade. Assim a pesquisa atual tem como questão norteadora:

"Quais são os conhecimentos dos estudantes do curso de graduação de enfermagem do segundo ao quarto ano, sobre a importância da passagem de plantão?”

Dessa forma o objetivo da pesquisa foi identificar o conhecimento dos graduandos de enfermagem sobre a importância da passagem de plantão.

\section{MÉTODo}

Trata-se de uma pesquisa de campo de abordagem qualitativa, realizada em uma instituição de ensino superior privada em uma cidade no interior do estado de São Paulo. Os participantes do estudo foram 
graduandos do curso de Enfermagem e a amostra obtida foi estabelecida por conveniência, a partir do interesse dos estudantes em participar do estudo. Os critérios de inclusão foram alunos de graduação em enfermagem que estivessem cursando o segundo, terceiro e quarto ano, pois vivenciam e cursam o ensino clínico e tem contato com a passagem de plantão. Critérios de exclusão alunos do primeiro ano, pois nesse período não participam dos estágios, momento em que poderiam vivenciar a realização da passagem de plantão e alunos que se recusassem a responder o questionário.

Antes de iniciar a coleta de dados foi realizado divulgação oral nas salas de aula sobre o desenvolvimento do estudo. Em datas combinadas com a coordenação do curso, as pesquisadoras foram novamente às salas de aula para realizar a coleta de dados, que ocorreu por meio de um questionário aberto que constou com quatro questões relacionadas a importância da passagem de plantão, o que deveria ser abordado nesse momento, fatores que poderiam interferir e também facilitar esse processo, visando alcançar o objetivo proposto. A coleta ocorreu durante o mês de junho de 2016, o tempo médio gasto para a resposta do questionário foi de 20 a 25 minutos.

Foram cumpridas todas as exigências da Resolução n 466, de 12 de dezembro de 2012 do Conselho Nacional de Saúde que regulamenta as normas para a realização de pesquisas que envolvem seres humanos (BRASIL, 2012). A pesquisa foi aprovada pelo Comitê de Ética em Pesquisa da instituição em que foi realizado o estudo, conforme (CAAE: 50385115.0.0000.5383), e os dados foram coletados após a assinatura do Consentimento Livre e Esclarecido (TCLE), no qual estavam explícitos o objetivo do estudo.

Cada ano do curso de enfermagem foi analisado separadamente, os sujeitos foram indicados da seguinte forma, S1/2 (sujeito do 2 ano de enfermagem), S1/3 (sujeito do 3 ano de enfermagem), S1/4 (sujeito do 4 ano de enfermagem), de maneira a garantir a confidencialidade dos participantes.

Para a análise dos dados foi realizada a Análise de Conteúdo Temático. Existem várias modalidades de análise de conteúdo, a utilizada foi a análise temática que consiste em descobrir os núcleos de sentido que compõem uma comunicação, cuja presença ou frequência signifique algo para o objetivo (MINAYO, 2014).

Após a leitura flutuante passou-se para a etapa da Constituição do Corpus, ou seja, separar as categorias encontradas, esse termo deve responder a algumas normas de validade qualitativa, exaustividade: o material deve contemplar todos os aspectos levantados no roteiro; representatividade: deve conter as características essenciais do universo pretendido; homogeneidade: tem de obedecer aos critérios preciosos de escolha quanto aos temas tratados, técnicas empregadas e atributos dos interlocutores; pertinência: adequação dos documentos analisados, dando resposta aos objetivos do trabalho (MINAYO, 2014).

A segunda etapa constou com a exploração do material em uma operação classificatória a fim de alcançar o núcleo de compreensão do texto. Para que isso ocorra é necessário que o pesquisador busque encontrar categorias que são expressões ou palavras significativas em função das quais o conteúdo de uma fala será organizado. Essa categorização consiste em processos de diminuição do texto, palavras e expressões significativas, sendo assim essa é uma etapa delicada, pois se não houver segurança nas escolhas de categorias leve a uma abordagem densa e rica(MINAYO, 2014).

A terceira e última etapa foi realizado o tratamento dos resultados obtidos e interpretação. Os resultados brutos foram analisados visando colocar em relevo as informações obtidas. Dessa forma, o analista realiza interpretações relacionadas com quadro teórico desenhado inicialmente ou abre caminhos para novas dimensões teóricas e interpretativas, sugeridas pela leitura do material (MINAYO, 2014).

\section{RESULTADOS E DISCUSSÃo}

Dos 81 estudantes matriculados entre o segundo e quarto ano do curso de Enfermagem, participaram da pesquisa 69 graduandos. A idade desses participantes foi entre 19 a 44 anos. No segundo ano de graduação $96 \%$ dos participantes eram do sexo feminino, terceiro ano $100 \%$ e no quarto ano $95 \%$ do sexo feminino. 


\section{SOTRATI et al.}

As categorias encontradas de acordo com a opinião dos graduandos sobre a importância da passagem de plantão foram : Conhecer o paciente; Continuidade do cuidado/ cuidado seguro; Estado geral do paciente e sua evolução; Pendências para o próximo plantão; Cuidados prestados/ ações de enfermagem; Intercorrências, pressa em finalizar o plantão e ir embora; Falta de comunicação e atenção; Comunicação prejudicada/ ruídos; Boa comunicação; ambiente adequado; Bom relacionamento em equipe; Uso de um instrumento como check list.

\section{Conhecer o PACIENTE}

É muito importante pois é um meio de comunicação com a equipe e nesse momento deve repassar as informações sobre a situação de cada paciente (S7/4).

É importante a passagem de plantão pois é o modo de sabermos como o paciente passou o dia, ou o que aconteceu durante esse período (S24/2).

É muito importante, pois você pode conhecer o paciente, quando ele é admitido, suas patologias, suspeitas de diagnósticos, como ele passou o dia e que cuidado ele vai precisar durante o plantão (S13/3).

\section{Continuidade do cuidado/ Cuidado Seguro}

É fundamental para uma continuidade eficaz e eficiente do cuidado prestado, permitindo a disseminação da informação para todos os turnos e promovendo um atendimento integral e resolutivo de forma organizada e sincronizada dentro da equipe. (S5/4)

Primordial para a continuidade eficaz e segura do cuidado e o paciente. (S1/3)

Para ter uma continuidade no processo de cuidado de enfermagem. (S25/2)

Mediante a importância da passagem de plantão, os graduandos de enfermagem conseguem perceber que esse momento permite trocar informações sobre o paciente, favorecendo o conhecimento do seu estado de saúde. Esse momento foi identificado pelos participantes como um momento que pode garantir a continuidade do cuidado seguro.

Os principais aspectos abordados durante a passagem de plantão são: as condições gerais de saúde e/ ou sua alteração e a conduta proposta; se algum exame foi realizado ou não; se o paciente está recebendo algum preparo para exame a ser feito e andamento do mesmo, assim como a presença de soros, drenos, sondas; modo de transporte (maca, cadeira, deambulando); informações sobre os materiais usados e a serem reposto, bem como as condições dos equipamentos. Além das condições gerais, também alterações, decisões tomadas e condutas propostas, bem como as condições administrativas da unidade (COREN, 2015).

Assim a passagem de plantão pode ser realizada visando atender um requisito relacionado ao planejamento da assistência de enfermagem, requerendo do profissional enfermeiro o resgate de conhecimentos e habilidades teórico prático e fazendo o profissional refletir sobre o cuidado prestado durante a rotina de trabalho. A partir dessas reflexões podem surgir mudanças nas futuras condutas visando alcançar um cuidado seguro para o paciente (MARQUES; SANTIAGO; FELIX, 2012).

A segunda questão abordou o conteúdo da passagem de plantão.

\section{Estado Geral do Paciente e sua Evolução}


Deve ser abordado todas as informações pessoais e estado de saúde do paciente, desde nome do paciente, idade, até nível de consciência, estado. (S17/4)

Na passagem de plantão deve ser abordado o estado físico, sociológico, social, espiritual do paciente, pontuando os mínimos detalhes ocorridos no plantão anterior com o paciente. Olhando as necessidades do paciente passando informações. (S20/3)

Como paciente se encontra se ele está 'bem' ou não. (S23/2)

\section{Pendências para o próximo plantão}

Deve ser abordado na passagem de plantão procedimentos que devem ser executados no próximo turno. (S2/4)

\section{Cuidados Prestados/Ações de enfermagem}

Deve ser abordado quais foram os procedimentos realizados no paciente. (S11/4)

\section{INTERCORRÊNCIAS}

Deve ser abordado se houve intercorrências durante o plantão, se há algum tipo de alteração no quadro clínico. (S13/4)

Deve ser abordado o estado de saúde, bem como, o psicológico e todos pacientes daquele setor, se durante o plantão houve alguma intercorrência ou não, se todos os procedimentos de horário foram realizados (S19/3).

As categorias apresentadas evidenciam que os graduandos conhecem os pontos mais relevantes que devem ser abordados nesse momento, como estado geral do paciente e sua evolução, pendências, cuidados prestados e intercorrências, porém as falas relacionadas a primeira categoria Estado Geral do Paciente e sua Evolução, não apresentam informações que deixem claro a análise desse estado geral, como achados do exame físico ou evolução clínica.

As informações que são consideradas importantes e relevantes devem girar em torno das intercorrências, condição clínica do paciente, questões administrativas da unidade, exames solicitados e realizados, medicações, acompanhantes, cuidados gerais e procedimentos realizados (GONÇALVES et al., 2016).

Para garantir a continuidade da assistência e alcançar resultados efetivos para a resolução de problemas relacionados aos clientes é necessária a passagem de plantão, ou seja, a mesma é um recurso estratégico para organizar o cuidado de enfermagem (COREN, 2015).

De acordo com o Código de Ética dos Profissionais de Enfermagem, no Artigo 16 da Seção I das relações com a pessoa, família e coletividade, dentre as responsabilidades e deveres desses profissionais:

"Art. 16 - Garantir a continuidade da assistência de enfermagem em condições que ofereçam segurança..." (COREN, 2015).

Deve ser um momento de reflexão sobre tudo o que foi realizado pela equipe multiprofissional, durante o turno de trabalho, discutir as intercorrências, as atitudes e decisões tomadas por cada agente da equipe na realização das atividades assistenciais. Este momento permite repensar os aspectos da assistência que ainda podem melhorar, (re) planejar, buscando alternativas para o trabalho de fato, proporcionando 


\section{SOTRATI et al.}

crescimento profissional e pessoal aos trabalhadores, além de favorecer a assistência ao paciente (TOBIAS, et, al., 2016, CARLOS, 2014).

Foi identificado na terceira questão o que poderia interferir na passagem de plantão:

\section{Pressa em finalizar o Plantão e ir EMbora}

O que pode interferir na passagem de plantão é a pressa dos funcionários para deixar o plantão, passagem incompleta de informações importantes. (S1/4)

Conversas paralelas, falta de informação, passar plantão muito rápido com coisas básicas demais, como paciente bem, dormiu bem, come, sem queixas. (S13/3)

Atraso no horário da chegada do profissional que irá dar continuidade no plantão, descaso do profissional. $(S 9 / 3)$

\section{Falta de Comprometimento e atenção}

Pode interferir a falta de atenção e comunicação entre as equipes ou falta de interesse. (S13/4)

A não aderência de todos profissionais por achar que esse momento é apenas por obrigação, não abordando todos os pontos necessários para uma boa transmissão de informações. Também o estresse dos profissionais no final de plantões cansativos. (S20/3)

Falta de atenção, falta de respeito, falta de profissionalismo, ética, postura. (S4/2) que trabalhou com as possíveis interferências durante esse processo, foram encontradas as seguintes categorias:

\section{Comunicação Prejudicada / Ruídos}

Ruídos e interferência, provocando desatenção, desconcentração e falhas na compreensão. (S8/4)

A falta de comunicação interfere diretamente na passagem de plantão, pois lacunas deixadas na informação passada pode interferir nos cuidados que serão prestados no paciente.(S16/3)

A falta de comunicação, pois as vezes tem acontecido algumas coisas durante o plantão que é importante e as vezes não passamos e acaba atrapalhando no atendimento melhor para o paciente. (S11/2)

Os fatores que interrompem a comunicação, fazendo com que não seja contínua e satisfatória são: ruídos dos monitores e aparelhos utilizados nas unidades, os atrasos e saídas antecipadas e as conversas paralelas entre os funcionários. Estes aspectos merecem atenção, uma vez que interferem na qualidade e continuidade das passagens de plantão. Outro fator que interfere, é o desconhecimento das informações mais importantes e relevantes a serem repassadas como medicamentos utilizados e exames realizados (GONÇALVES et al., 2016).

Os fatores como o comportamento e atitude dos profissionais durante a passagem de plantão, também a falta de conhecimento e percepção dos profissionais quanto a importâncias da comunicação, as interrupções, conversas paralelas, atrasos, saídas antecipadas e ruídos, são ações negativas a segurança do paciente (GONÇALVES et al., 2016).

A passagem de plantão é capaz de oferecer aos membros da equipe um momento de análise do estado 
geral do paciente além das exigências referentes a assistência necessária, porém muitos são os conflitos e dificuldades encontrados pela equipe durante a passagem de plantão, dentre elas a a desatenção, o envolvimento parcial dos profissionais, bem como a falta de informações importantes ou simplesmente a omissão delas, podem acarretar em danos ao paciente, à equipe e também a instituição (TOBIAS, et. al.; 2016).

Percebe-se ainda, a desvalorização da atividade na prática de enfermagem, a falta de compromisso com a mesma quando se destacam comportamentos inadequados por parte dos profissionais como conversas paralelas e existência de desrespeito com aquele que repassa as informações. Além de outros desafios como o número reduzido de profissionais que compõem a equipe, a sobrecarga de trabalho e a necessidade de realização de tarefas em tempo reduzido (TOBIAS, et. al.; 2016).

As categorias apresentadas mostram as percepções dos alunos mediante a pressa em finalizar o plantão, a falta de comprometimento e atenção dos próprios profissionais, e os ruídos que podem trazer prejuízos nesse momento. Assim implicações decorrentes dessa falha passam pelo processo de comunicação entre os membros da equipe nos diversos turnos até aspectos éticos comportamentais, como o envolvimento parcial dos profissionais, assim como a omissão de informações importantes, podem interferir na passagem de plantão (MARQUES; SANTIAGO; FELIX, 2012).

A quarta questão identificou os possíveis facilitadores para realizar a passagem de plantão

\section{Boa comunicação / Ambiente Adequado}

Uma boa comunicação entre as equipes, coerência durante a passagem, informações necessárias para continuar o plantão. (S13/4)

Acho que deveria na hora da passagem de plantão todos os profissionais devem se comunicar com outros de forma clara e objetiva, pontuando o que deverá ser feito os cuidados, pontuando o que é importante sobre o paciente. (S14/3)

Organizar o tempo e realizar a passagem de plantão de forma clara e calma, sem correria, abordando todos os pontos importantes que ocorreram no plantão. (S19/3)

Comunicação clara e objetiva, ambiente tranquilo. (S20/2)

\section{BOM RELACIONAMENTO EM EQUIPE}

Um bom relacionamento entre os profissionais dos plantões, esclarecimentos da importância para os funcionários. (S1/4)

Boa comunicação e convivência com os próximos que estão entrando, companheirismo. (S7/3)

Facilita se houver trabalho em equipe, ética e respeito. (S7/2)

\section{USO DE UM INSTRUMENTO COMO CHECK LIST}

Acredito que um check list com todas os componentes necessários ajudaria na passagem de plantão e ficaria padronizado. (S18/4)

Passar plantão é um acontecimento onde se faz necessário transmitir informações da melhor maneira possível para que estas sejam passadas de forma clara e objetiva, mas também concisa para assim garantir 


\section{SOTRATI et al.}

o bom entendimento e o fluxo das informações pertinentes.

É um cenário complexo de trabalho que exige uma comunicação efetiva, é preciso pensar no circuito da comunicação em todos os seus componentes na atividade de passagem de plantão, incluindo mensagens que são emitidas, o modo como se faz a emissão das mensagens pelo comunicante e a maneira como o receptor recebe a mensagem, além do tempo existente para a atividade e o envolvimento dos agentes comunicantes e receptor do processo. Assim as relações interpessoais envolvidas nesse processo ganham importância para que a atenção esteja voltada para esse momento, para que o receptor esteja atento nesse processo (MARQUES; SANTIAGO; FELIX, 2012, FARIAS et, al. 2010).

Existe uma recomendação de capacitar a equipe para uma adequada comunicação entre os profissionais utilizando estratégias que facilitem a compreensão da mensagem. Já em relação ao ambiente adequado para esse processo, alguns estudos apontam que os profissionais envolvidos na passagem de plantão valorizam a característica do relato verbal e ainda caracterizam como positiva a passagem de plantão realizada em ambiente reservado e não à beira do leito do paciente, pois entendem que desta forma acaba expondo os pacientes perante familiares e até mesmo outros pacientes (CARLOS, 2014; MARTINEZ, TOCANTINS, SOUZA, 2013).

Em relação a utilização de um impresso (check list) para a passagem de plantão torna a atividade prática, otimiza o tempo, sendo rápido e fácil seu preenchimento, além de abordar informações relevantes para a continuidade do cuidado ao paciente, por conter maior numero de informações pertinentes aos cuidados (MAZZI; TONHOM, 2014).

A elaboração de um roteiro tem por finalidade auxiliar na superação das dificuldades de alguns profissionais de estabelecer um jeito apropriado de realização da atividade. $O$ uso de checklist pode auxiliar na tomada de decisão favorecendo a segurança do paciente, além de favorecer um diálogo e a execução de atividades que todos julguem pertinentes para um bom resultado. Partindo do princípio de que uma passagem de plantão melhor estruturada e padronizada tende a diminuir erros, refletindo em maior segurança à equipe e ao paciente (SILVA, 2012).

Sendo assim o check list unifica as informações acerca do estado de saúde do paciente, contribuindo para uma comunicação eficaz durante a passagem de plantão, de modo a reduzir a ocorrência de erros e também repercutir na segurança do paciente (SILVA, 2012).

Existe a técnica ou metodologia SBAR (situação, background, avaliação e recomendação) que é um método padronizado e simples de comunicar informações importantes, de forma clara e concisa. Pode ser utilizado em várias situações como, por exemplo, na passagem de plantão e transferência do paciente de uma unidade para outra. Na técnica SBAR, situação corresponde ao enunciado conciso do problema; background, à informação pertinente e breve acerca da situação/problemas; avaliação, à analise e opção de resolução/encaminhamento e recomendação à ação necessária/recomendada (GONÇALVES et al., 2016; BRASIL, 2016).

Segundo os graduandos de enfermagem, alguns facilitadores para a passagem de plantão são: manter uma boa comunicação, manter um ambiente adequado, ter um bom relacionamento com a equipe e como sugestão utilizar um instrumento como check list para que o tempo gasto seja reduzido. Treinamentos envolvendo relação interpessoal e comunicação podem facilitar essa temática (GONÇALVES et al., 2016; BRASIL, 2016).

Nesse momento da troca de informações alguns pontos podem ser fortalecidos como os vínculos sociais, a garantia de que os dados essenciais sejam transferidos para a segurança do paciente e assim evitar que condutas inadequadas sejam tomadas, assim como possíveis atrasos no tratamento, isso porque algumas falhas na comunicação podem gerar todo um prejuízo na decisão terapêutica do paciente. Prevenção de falhas na comunicação pode ter inicio com uma comunicação estruturada (HALM, 2013; POTT, et. al.; 2013). 
De acordo com os resultados os graduandos reconhecem a passagem de plantão como uma ferramenta importante para garantir a continuidade do cuidado seguro. Devendo ser abordado o estado geral do paciente, intercorrências, pendências para o próximo plantão e os cuidados que já foram prestados durante aquele plantão que se finalizou.

Ficou evidenciado alguns fatores que podem interferir na passagem de plantão, sendo um dos principais a comunicação prejudicada, a pressa em finalizar o plantão, a falta de comprometimento e atenção dos profissionais. Entre as possíveis melhorias apontadas pelos alunos estão boa comunicação entre a equipe, ambiente adequado, livre de ruídos e o uso de instrumentos como o check-list.

\section{CONSIDERAÇões Finais}

Contudo a importância da comunicação e da passagem de plantão na atuação do profissional enfermeiro é um fato que precisa ser aprendido desde a sua formação acadêmica. Ainda existem diversos desafios que precisam ser superados como a compreensão da importância desse momento como algo que pode interferir diretamente na assistência prestada e no cuidado oferecido. Porém essa compreensão precisa ser desenvolvida desde o período de formação desses profissionais.

A formação acadêmica é o momento onde hábitos relacionados a segurança do paciente podem ser construídos. Assim, durante o processo de formação é fundamental a abordagem e discussão dessa temática para a valorização do cuidado seguro e de qualidade. É importante que novas pesquisas abordem essa temática com a finalidade de valorizar esse processo e gerar profissionais que utilizem a comunicação como um auxílio no seu cuidado humanizado, qualificado e seguro. Formando assim profissionais mais habilitados a desenvolverem essa prática.

\section{REFERÊNCIAS}

BRASIL. Ministério da Saúde. Conselho Nacional de Saúde. Resolução n. 466, de 12 de dezembro de 2012. Diário Oficial da União, Brasília, DF, 13 jun. 2013b. Seção 1, p. 59.

BRASIL. Ministério da Saúde. Programa Nacional de Segurança do Paciente.Disponível em: <http:// portalsaude.saude.gov.br/index.php/o-ministerio/principal/secretarias/sas/dahu/seguranca-do-paciente > Acesso em 10 ago. 2016.

BROCA, P. V; FERREIRA, M. A. Equipe de enfermagem e comunicação: contribuições para o cuidado de enfermagem. Rev. Bras. Enferm, Brasília, v. 65, n.1, p. 97- 103, jan., 2012.

CARLOS, A. M. M. Um novo modo de fazer a passagem de plantão da enfermagem. 2014. $135 \mathrm{f}$. Dissertação (Mestrado Profissional) - Programa de Pós-graduação Gestão do Cuidado de Enfermagem, Universidade de Santa Catarina, Florianópolis, 2014.

CONSELHO REGIONAL DE ENFERMAGEM DE SÃO PAULO. Parece COREN- SP 041/2013. Ementa Passagem de Plantão no turno seguinte. Quando se caracteriza -se abandono de plantão. São Paulo, jun 2013. Disponível em: < http://portal.coren-sp.gov.br/sites/default/files/parecer_coren_sp_041_2013. pdf> Acesso em: 23 maio 2015.

FARIAS, L. M. et al. Comunicação proxêmica entre a equipe e o recém nascido na unidade neonatal. Rev. Rene, Fortaleza, v. 11, n. 2 , p. 43- 37, 2010. 


\section{SOTRATI et al.}

GOLÇALVES, M. I. et al. Comunicação e segurança do paciente na passagem de plantão em unidades de cuidados intensivos neonatais. Texto \& Contexto - Enfermagem, Santa Catarina, v. 25, n 1, p.1-8, 2016. HALM, M. A. Nursing handoffs: ensuring safe passage for patients. American Journal of Critical Care, v. 22 n. 2, p. 158-62, 2013.

MARQUES, L. F; SANTIAGO, L. C; FELIX, V. C. A passagem de plantão como elemento fundamental no processo de cuidar em enfermagem: $\mathrm{O}$ perfil da equipe de enfermagem de um hospital universitário. Rev pesqui cuid fundam. v. 4, n. p. 2878-82, 2012.

MARTINEZ, E. A; TOCANTINS, F. R; SOUZA, S. R. As especificidades da comunicação na assistência de enfermagem à criança. Rev. Gaúcha Enferm, Porto Alegre, v. 5, n. 1, 2013. Disponível em <http:// www.scielo.br/scielo.php?script=sci_arttext\&pid=S1983-14472013000100005\&lng=en\&nrm=iso $>$ Acesso em: 30 mar. 2015.

MAZZI, N. R; TONHOM, S. F. R. Visita pré-operatória de enfermagem: validação de um instrumento. Revista Eletrônica Acervo Saúde, v. 6, n. 2, p.638-645, 2014.

MINAYO, M. C. S. O desafio do conhecimento. Pesquisa qualitativa em saúde. São Paulo: Hucitec editora. p. 316, 317, 2014.

POTT, F. S. et al. Medidas de conforto e comunicação nas ações de cuidado de enfermagem ao paciente crítico, Rev Bras Enferm, Brasília. v. 66, n. 2, p. 179-174, 2013.

SILVA, M. F. A comunicação na passagem de plantão de enfermagem e sua repercussão na segurança do paciente pediátrico. 2012. 115f. Tese (Doutorado), Universidade Federal de Santa Catarina. Florianópolis, 2012.

SOUSA, S. M; BERNARDINO, E. Gerenciamento de enfermagem para o cuidado integral: revisão integrativa. Rev enferm UFPE, Recife. v. 9, n. 6, p. 8312-21, 2015.

TOBIAS, G. C. et al. Cultura de segurança em hospital de ensino: fortalezas e fraquezas percebidas por enfermeiros. Rev enferm UFPE on line, Recife, v.10 n. 3, p.1063-70, 2016. 